\title{
Analysis of Influence of Types of Rocks Forming the Goaf with Caving on the Physical Parameters of Air Stream Flowing Through These Gob and Adjacent Headings
}

\author{
Jarosław BRODNY*, Magdalena TUTAK**, Antoni JOHN*** \\ *Silesian University of Technology, Faculty of Organization and Management, Roosevelta 26-28, 41-800 Zabrze, Poland, \\ E-mail: jaroslaw.brodny@polsl.pl \\ **Silesian University of Technology, Faculty of Mining and Geology, Akademicka 2, Gliwice 44-100, Poland, \\ E-mail: magdalena.tutak@polsl.pl \\ ***Silesian University of Technology, Faculty of Mechanical Engineering, Konarskiego 18A, Gliwice 44-100, Poland, \\ E-mail: antoni.john@polsl.pl
}

crossref http://dx.doi.org/10.5755/j01.mech.24.1.20214

\section{Introduction}

One of the most important problems occurring during ventilation of longwall headings in hard coal mining is an air migration of air through the goaf with caving of these headings [1-3]. Part of air stream supplied to the longwall is separate into two streams - one flows into the longwall, second goes to the gob (Fig. 1).

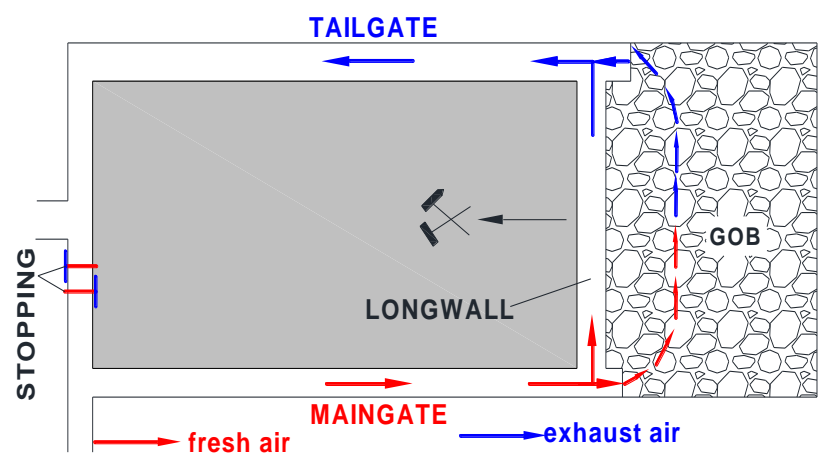

Fig. 1 Scheme of air distribution within the longwall and gobs

This process causes decrease of amount of fresh air incoming into longwall and increase of ventilation hazards in this region. Air coming into the gobs contains oxygen, which can contribute to formation of endogenous fire [2, 3, 4]. This air can cause outflow of methane to the longwall headings and to the operating area of the longwall [5]. Both phenomena are very dangerous for the crew and infrastructure present in this region. It can cause inflammation and/or explosion of methane and self-ignition of coal remaining in goaf with caving (endogenous fires). Therefore, in exploitation process one aims to reduce amount of air flowing into gobs area. Amount of inlet air to the gobs significantly depends on their permeability.

Goaf with caving are rock rubbles formed in result of breaking down of roof rocks after mining the usable mineral (in this case a hard coal). As a result of this process, porous medium with determined permeability and porosity is formed. Permeability of gobs is dependent on degree of filling of the selected surface through created rubble and type of roof rocks forming this rubble. Robust and compact roof rocks make packing of cracked rock blocks looser and make them harder to transit into fall state, which causes that formed caving is not very tight and has large permeability. Weak and brittle rocks transit more easily into fall state, thus the fall is characterized by higher sealing and lower permeability $[1,6]$. Therefore, it is reasonable to conclude that type of roof rocks forming caving has significant impact on the degree of filling gobs so their permeability. This subsequently decides about amount of air incoming into the heading.

Results of tests in underground conditions indicate that in a case of gobs with a high permeability there can flow about $35 \%$ of air supplied to this longwall heading [1]. It is necessary to determine what impact on permeability of gobs has the type of rocks forming gobs. Execution of these tests in real conditions is very expensive, dangerous and practically impossible to carry out. Goaf with caving are inaccessible for researchers. Therefore, it is necessary to use other research methods in order to determine impact of type of the rocks forming goaf with caving on their permeability. Such possibilities create modelling studies. In order to perform such studies and obtained credible results it is necessary to determine properties of roof rocks having impact on quality of forming caving.

Parameter which characterizes roof rocks due to the permeability of formed gobs from these rocks is destratification resistance. In the paper, there is assumed that value of destratification resistance of roof rocks forming caving has decisive impact on degree of filling of selected area, and thus on the permeability of created goaf with caving.

Assuming this assumption based on stand tests values of destratification resistance for different types of roof rocks presented in roof of mining heading were determined. Then, the geometrical and mathematical models of real system of mining headings together with goaf with caving were developed. Physical parameters of air stream flowing through this heading were determined based on real tests. Goaf with caving were modelled as porous medium with permeability depending on destratification resistance of rocks forming these gobs. Numerical tests were performed using ANSYS Fluent software. This software gives a lot of opportunities within determination of parameters of gases flow and their distributions, also eliminates inaccuracies connected with possible measurement mistake.

The main aim of studies carried out was to determine impact of type roof rocks forming goaf with caving on the physical parameters of air stream flowing through the 
longwall heading and these gobs. Utilization of results of performed tests in real conditions enabled to partial validation of obtained results from numerical analysis. Satisfied results of this process confirmed correctness of developed methodology, which can be applied to forecast of ventilation parameters in the longwall headings. Tests were performed for real system of rocks and for two additional variants of roof rocks forming caving.

In the paper also the way for determination of the impact of type of roof rocks on nonlinear distribution of permeability in porous rock medium was described. Also results of simulation for different geomechanical parameters of rocks forming goaf with caving were presented.

Using for analysis modelling tests can be an additional source of information necessary to perform safe mining exploitation process. Also it should be emphasized, that application of computational fluid dynamics (CFD) enables to very precisely determine the ventilation parameters of air at any point of tested mining heading, including goaf with caving. Determination of these parameters based on tests in real conditions in a case of air flow through the longwall of goaf with caving is impossible.

\section{Determination of impact of type of roof rocks on per- meability of goaf with caving}

The coefficient value of gobs permeability depends on rocks types forming caving. Parameter characterize these rocks (roof) in respect to their permeability is their stratification resistance.

Destratification resistance of rocks is natural capability of the rock mass to oppose stratification and caving of roof rock to the heading surface. This capability is equal to the tensile strength of the forces directed vertically [6].

Destratification resistance of rocks is determined based on laboratory tests using downhole penetrometers or by disruption segments of vertical drilling of bore in the direction of longitudinal axis of opening. Value of this resistance is determined based on dependence:

$$
R_{r r i}=0.8 \frac{F}{d^{2}}
$$

where: $R_{r r i}$ is destratification resistance of rocks $(\mathrm{Pa}), F$ is the tensile strength $(\mathrm{Pa}), d$ is diameter $\left(\mathrm{m}^{2}\right)$.

The resistance of roof rock stratification forming caving is calculating from dependence [1]:

$$
R_{r r s}=\frac{\sum_{i=1}^{n} R_{r r i} m_{i}}{\sum_{i=1}^{n} m_{i}},
$$

where: $R_{r r s}$ is resistance of roof rock stratification $(\mathrm{Pa}), m_{i}$ is the thickness of layers $(\mathrm{m})$.

Resistance of roof rock stratification calculated on the basis of Eq. (2), enables to determine permeability coefficient of goaf with caving from Eq. (3) and Eq. (4) [1]:

$$
\begin{aligned}
& k(x)=\frac{\mu_{g}}{r_{0}+a x^{2}}, \text { for } 0 \leq x \leq \frac{2}{3} l, \\
& k(x)=\frac{\mu}{r_{0}+a\left(\frac{4}{3} l-x\right)^{2}}, \text { for } \frac{2}{3} l \leq x \leq 1,
\end{aligned}
$$

where: $k(x)$ is permeability coefficient of gob $\left(\mathrm{m}^{2}\right), \mu_{g}$ is the coefficient of dynamic viscosity $\left(\mathrm{Nsm}^{-2}\right), l$ is the total length of the longitudinal longwalls $(\mathrm{m}), r_{0}, a$ are empirical factor depending on the mining-geological conditions gobs.

In Table 1 examples of values of permeability coefficient of gobs for different type of roof rocks and different distance from the front longwall (for lenght of the goaf with caving is 400.0), calculated based on dependences 3-4 are given.

Values of permeability coefficient of gobs for different type of rocks and different distance from the longwall

\begin{tabular}{|c|c|c|c|c|c|}
\hline \multirow{2}{*}{$\begin{array}{c}\text { Type of rocks, } \\
\text { Value of } R_{r r s}, \mathrm{MPa}\end{array}$} & \multicolumn{5}{|c|}{ Values of permeability coefficient of gobs, $\mathrm{m}^{2}$} \\
\cline { 2 - 6 } & \multirow{2}{*}{ For $\boldsymbol{R}_{r r s}, \mathrm{MPa}$} & \multicolumn{4}{|c|}{ Distance from the longwall face, $\mathrm{m}$} \\
\cline { 2 - 6 } & 0.5 & 50 & 100 & 200 & 400 \\
\hline \multirow{2}{*}{ Shale, $0.5 \div 1.5$} & 1.5 & $5.21 \cdot 10^{-9}$ & $2.35 \cdot 10^{-9}$ & $6.10 \cdot 10^{-10}$ & $1.36 \cdot 10^{-9}$ \\
\cline { 2 - 6 } & 2.0 & $8.42 \cdot 10^{-8}$ & $2.56 \cdot 10^{-8}$ & $6.70^{-8} \cdot 10^{-9}$ & $9.09 \cdot 10^{-9}$ \\
\hline \multirow{2}{*}{ Mudstone, $1.5 \div 3.0$} & 3.0 & $1.65 \cdot 10^{-7}$ & $5.13 \cdot 10^{-8}$ & $1.37 \cdot 10^{-8}$ & $3.01 \cdot 10^{-8}$ \\
\hline \multirow{2}{*}{ Sandstone, $3.0 \div 4.5$} & 3.5 & $2.14 \cdot 10^{-7}$ & $6.69 \cdot 10^{-8}$ & $1.79 \cdot 10^{-8}$ & $3.93 \cdot 10^{-8}$ \\
\cline { 2 - 6 } & 4.0 & $2.67 \cdot 10^{-7}$ & $8.41 \cdot 10^{-8}$ & $2.25 \cdot 10^{-8}$ & $4.94 \cdot 10^{-8}$ \\
\hline \multirow{2}{*}{ Sandstone, $4.5 \div 6.0$} & 4.5 & $3.24 \cdot 10^{-7}$ & $1.02 \cdot 10^{-7}$ & $2.76 \cdot 10^{-8}$ & $6.06 \cdot 10^{-8}$ \\
\cline { 2 - 6 } & 6.0 & $5.21 \cdot 10^{-7}$ & $1.68 \cdot 10^{-7}$ & $4.54 \cdot 10^{-8}$ & $9.95 \cdot 10^{-8}$ \\
\hline \multirow{2}{*}{ Sandstone, $>6.0$} & 7.0 & $6.72 \cdot 10^{-7}$ & $2.19 \cdot 10^{-7}$ & $5.93 \cdot 10^{-8}$ & $1.297 \cdot 10^{-7}$ \\
\cline { 2 - 6 } & 8.0 & $8.37 \cdot 10^{-7}$ & $2.75 \cdot 10^{-7}$ & $7.48 \cdot 10^{-8}$ & $1.63 \cdot 10^{-7}$ \\
\hline \multirow{2}{*}{ Coal, $0.5 \div 3.0$} & 0.75 & $1.62 \cdot 10^{-8}$ & $4.73 \cdot 10^{-9}$ & $1.23 \cdot 10^{-9}$ & $2.74 \cdot 10^{-9}$ \\
\cline { 2 - 6 } & 2.75 & $1.43 \cdot 10^{-7}$ & $4.421 \cdot 10^{-8}$ & $1.18 \cdot 10^{-8}$ & $2.59 \cdot 10^{-8}$ \\
\hline
\end{tabular}

\section{Mathematical models}

The airflows at the maingate, tailgate and longwall are simulated as fully developed turbulent flow by using an $\mathrm{k}-\varepsilon$ model. Because laminar flow, transition flow and turbulent flow coexist in the goaf, the flow through the gob is treated as a non-darcy flow. For porous material analysis, like agoaf with caving, can be also used model of foam structures with open cells presented in [7].

\subsection{Basic flow equations}

System of balance equations of mass, momentum and energy (equations of fluid handling) of one-component 
flow takes the following form [8]:

$$
\begin{gathered}
\frac{\partial}{\partial t}(\rho)+\operatorname{div}(\rho \vec{v})=0, \\
\frac{\partial}{\partial t}(\rho \vec{v})+\operatorname{div}(\rho \vec{v} \vec{v})=\operatorname{div}(-p \stackrel{\leftrightarrow}{I}+\stackrel{\leftrightarrow}{\tau}+\stackrel{\leftrightarrow}{\tau})+\rho \vec{s}_{p}, \\
\frac{\partial}{\partial t}(\rho \vec{v})+\operatorname{div}(\rho e \vec{v})= \\
=\operatorname{div}\left[(-p \stackrel{\leftrightarrow}{I}+\stackrel{\leftrightarrow}{\tau}+\stackrel{\leftrightarrow}{\tau}) \vec{v}+\vec{q}_{s}+\vec{q}_{s}\right]+\rho s_{e} .
\end{gathered}
$$

System of equations (5-7) in a vector form can be written as [8]:

$$
\begin{aligned}
& \frac{\partial}{\partial t}\left(\begin{array}{l}
\rho \\
\rho \vec{v} \\
\rho e
\end{array}\right)+\operatorname{div}\left(\begin{array}{c}
\rho \vec{v} \\
\vec{v} \vec{v}+p \stackrel{\leftrightarrow}{I} \\
\vec{v}+p \stackrel{\leftrightarrow}{I} \vec{v}
\end{array}\right)=
\end{aligned}
$$

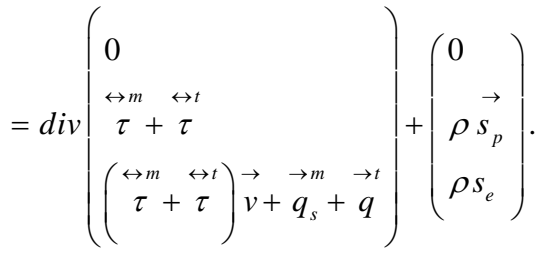

are [8]:

Variables presented in the system of equation (5-8)

$$
\left\{\rho, \vec{v}, p, \stackrel{\leftrightarrow}{\tau}, \underset{\leftrightarrow}{\tau}, s_{p}, e, s_{e}, q_{s}, q_{s}\right\},
$$

where: $p$ is the static pressure $(\mathrm{Pa}), V_{x}, V_{y}$ and $V_{z}$ are the air velocity $(\mathrm{m} / \mathrm{s}), C_{l}$ is the factor of viscous resistance $\left(1 / \mathrm{m}^{2}\right)$, $C_{2}$ is the factor of inertial resistance $(1 / \mathrm{m}), \rho$ is the fluid density $\left(\mathrm{kg} / \mathrm{m}^{3}\right)$.

Their number is greater than the number of equation. Therefore, this system must be complete with additional dependences.

In a case of modelling of flow through the porous medium such as goaf with caving, infiltration of presented system of equations is possible by introducing into balance equations additional factors.

This factor influences on macroscopic increase of movement resistance. The movement resistances brake momentum of fluid flowing through porous medium and acting on hole volume ot this medium. In such conception part of balance momentum equation should be modified.

Source of resistance can be in a form of Forchheimer eqaution which in three-dimensional space has a form [9, 10]:

$$
\begin{aligned}
& -\frac{\partial p}{\partial x}=C_{1} \mu V_{x}+C_{2} \frac{1}{2} \rho|V| V_{x}, \\
& -\frac{\partial p}{\partial y}=C_{1} \mu V_{y}+C_{2} \frac{1}{2} \rho|V| V_{y},
\end{aligned}
$$

$$
-\frac{\partial p}{\partial z}=C_{1} \mu V_{z}+C_{2} \frac{1}{2} \rho|V| V_{z}
$$

Combined with Eq. (10) - (12), the viscous resistance coefficient $C_{1}$ and the inertial resistance coefficient $C_{2}$ in ANSYS Fluent are determined from the dependence:

$$
\left\{\begin{array}{l}
C_{1}=\frac{1}{k} \\
C_{2}=\frac{2 \beta D_{m}}{k n}
\end{array} .\right.
$$

3.2. Model of air leakage resistance coefficient in the goaf

Nonlinear equation of movement describes filtration (flow) in porous medium given by Bachamt, has a form $[4,11]$ :

$$
-h=(a+b|V|) \vec{V},
$$

where: $h$ is the pressure head $(\mathrm{m}), \mathrm{V}$ is the fluid velocity $(\mathrm{m} / \mathrm{s}), a$ and $b$ are scalar coefficients in Eq. (14) and can be expressed by Eq. (15):

$$
\left\{\begin{array}{l}
a=v /(g \cdot k) \\
b=\beta \cdot D_{m} /(g \cdot n \cdot k)
\end{array},\right.
$$

where: $g$ is the acceleration of gravity $\left(9.81 \mathrm{~m} / \mathrm{s}^{2}\right), n$ is the porosity, $v$ is the kinematic viscosity $\left(\mathrm{m}^{2} / \mathrm{s}\right), k$ is the permeability of porous media $\left(\mathrm{m}^{2}\right), \beta$ is the shape factor of the media particles (1.5) and $D_{m}$ is the harmonic average particle size $(0.1 \mathrm{~m})$.

The porosity can be obtained by $K$, which is the coefficient of the bulk increase of caving rocks in the gob:

$$
n(x, y, z)=1-\frac{1}{K(x, y, z)} .
$$

\section{Simulation of the flow field of the longwall and the goaf with caving}

The tested longwall is a longitudinal system with caving roof in the direction from boundary and its mining parameters are equaled: length of the longwall is $220.0 \mathrm{~m}$, lenght of the goaf with caving is $300.0 \mathrm{~m}$, vertical height of the longwall is $3.0 \mathrm{~m}$, transverse slope is $4^{\circ}$ and longitudinal slope is $8^{\circ}$. In this paper, the flow rate of the maingate is set to $1080 \mathrm{~m}^{3} / \mathrm{min}$. U type ventilation system is applied to the working face.

Parameters characterizing rocks littering in roof of exploited longwall and forming goaf with caving are presented in a Table 2 .

In order to determine the impact of type of roof rocks forming caving on parameters of air stream flowing through these goaf with caving additional tests were performed for two additional variants of these rocks. Their parameters are presented in Table 3.

Using Equations $2-4$ permeability of goaf with caving were determined for real exploited longwall and for two alternative variants of rocks forming caving. 
Parameters characterizing rocks littering in roof of longwall and forming goaf with caving

\begin{tabular}{|c|c|c|c|}
\hline Type of roof rocks & Compressive strength, MPa & Tensile strength, MPa & $R_{r r s}, \mathrm{MPa}$ \\
\hline Clay slates with coal lamina & 17,50 & 2,08 & 3,88 \\
Coarse-grained & 24,60 & 2,30 & \\
Sandstones & 53,60 & 6,10 & \\
\hline
\end{tabular}

Table 3

Parameters characterizing rocks littering in roof of longwall and forming goaf with caving for alternative variants

\begin{tabular}{|c|c|c|c|c|}
\hline Alternative variants & Type of roof rocks & Compressive strength, $\mathrm{MPa}$ & Tensile strength, MPa & $R_{r r s}, \mathrm{MPa}$ \\
\hline \multirow{3}{*}{ I } & Clay slates with coal lamina & 14,40 & 2,70 & \multirow{3}{*}{4,24} \\
\hline & Clay slates & 17,40 & 3,0 & \\
\hline & Sandstones & 58,10 & 7,15 & \\
\hline \multirow[b]{2}{*}{ II } & Clay slates & 25,50 & 2,15 & \multirow[b]{2}{*}{3,31} \\
\hline & $\begin{array}{l}\text { Coarse-grained and fine- } \\
\text { grained sandstones }\end{array}$ & 51,90 & 4,60 & \\
\hline
\end{tabular}

\subsection{Results and discussion}

In order to perform the modelling tests, a geometrical, physical and mathematical models of investigated area were developed. In the investigated system the longwall was ventilated in the $U$ system.

In Fig. 2 geometrical model of tested longwall with marked measurement lines is presented. Also it was assumed that the vertical extent of airflow in rockfall goaves will be equal to 3.5 - times of the height of exploited seam.

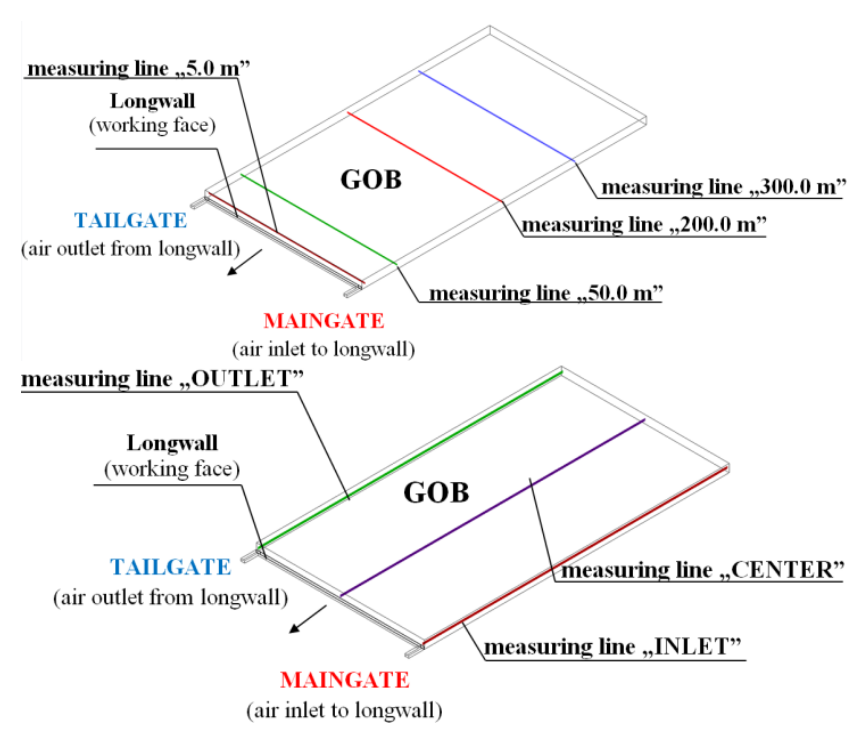

Fig. 2 The geometrical model with measuring lines

Such developed models were performed to analysis. The aim was to determine distribution of physical parameters of air stream flowing through these gobs.

Way of air distribution in the gobs for real system of roof rocks is presented in Fig. 3 .

In Figs. 4 and 5 there are presented characteristics of pressure changes in gobs for tested variants of roof rocks. Pressure distribution in gobs impact on velocity of airflow, and in consequences on formation of ventilation hazard in gobs and adjacent headings.

Based on obtained results one can conclude that the lower value of destratification resistance of rocks forming the goaf with caving, the bigger difference of air pressure flowing through these gobs, and the greater resistances of this flow. Rocks with lower strength on extension and value of destratification resistance cause greater resistances of airflow.

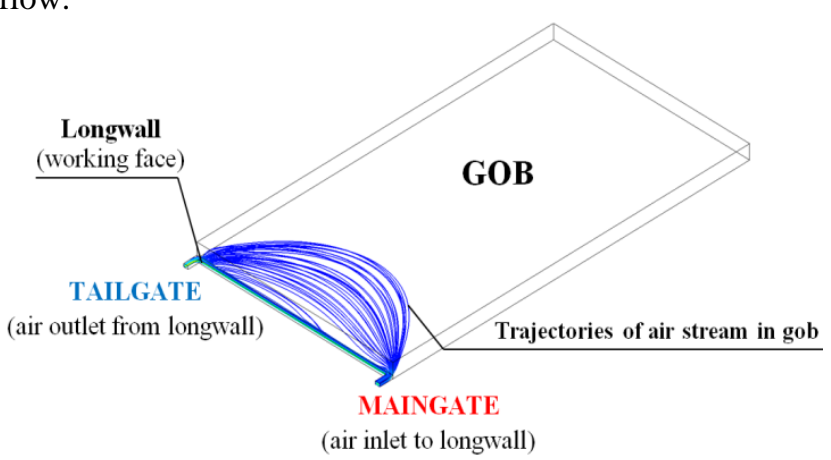

Fig. 3 Trajectories of air stream flowing through goaf with caving

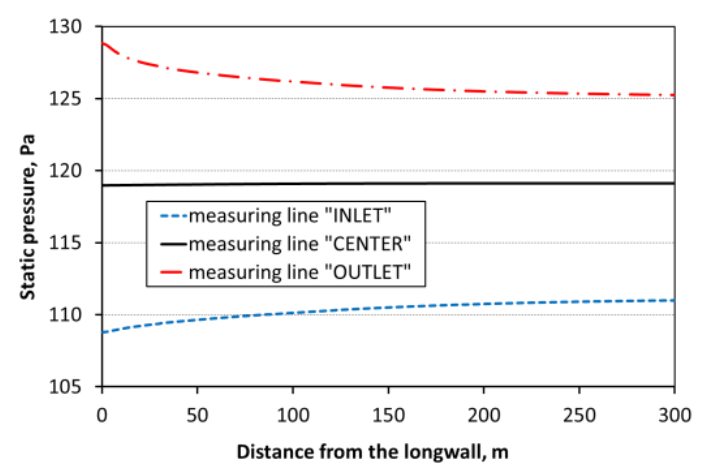

Fig. 4 Changes of static pressure values in goaf with caving for $R_{r r s}=3.31 \mathrm{MPa}$

In Figs. 7, 8 and 9 there are presented characteristics of velocity distribution of air stream flowing through gobs forming by rocks with different value of destratification resistance along to measurement lines situated perpendicular to the front of the longwall.

Distribution of velocity of air stream flowing through goaf on measurement lines ,inlet” perpendicular to the front of the longwall. Obtained results indicate that the biggest velocity of air in goaf with caving is presented for rocks with destratification resistance equals $4.24 \mathrm{MPa}$. Independently from value of destratification resistance of 
rocks the greatest values of velocity occur from the inlet side of goaf with caving and from the air outlet from gobs to the operating area of longwall.

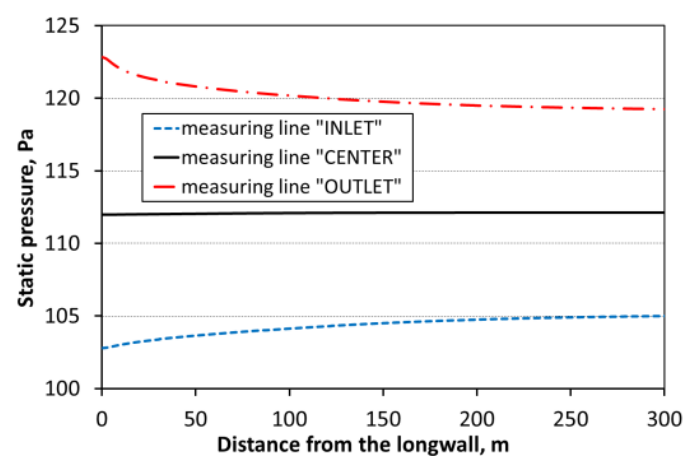

Fig. 5 Changes of static pressure values in goaf with caving for $R_{r r s}=3.88 \mathrm{MPa}$

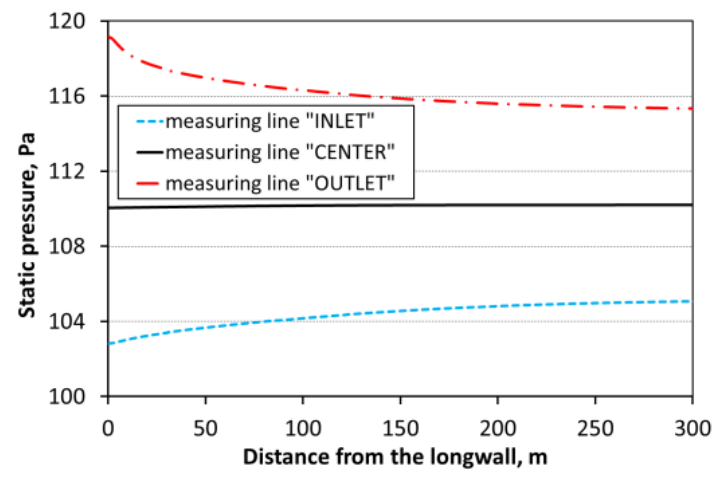

Fig. 6 Changes of static pressure values in goaf with caving for $R_{r r s}=4.24 \mathrm{MPa}$

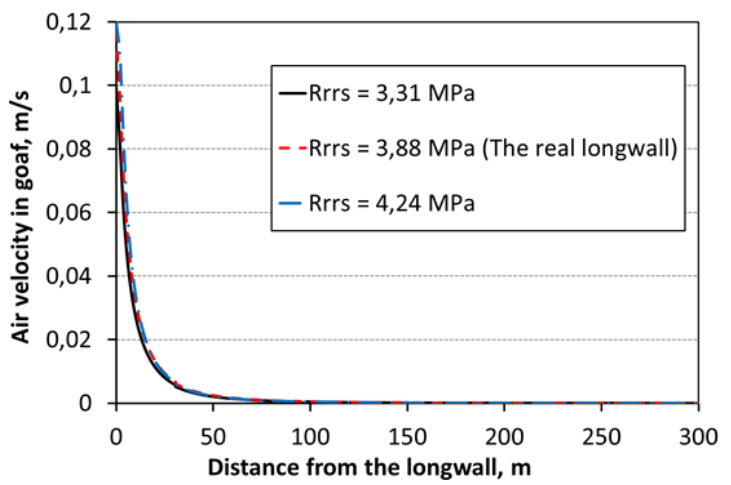

a

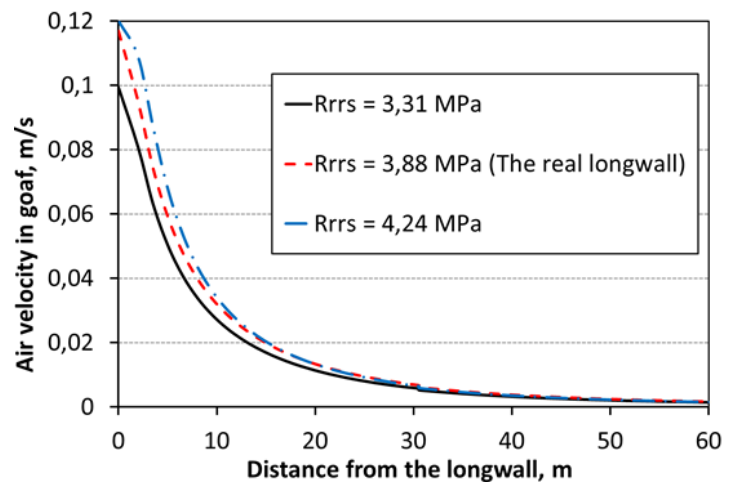

b

Fig. 7 Courses of changes in velocity of air flowing through the gob along the measurement line "INLET“

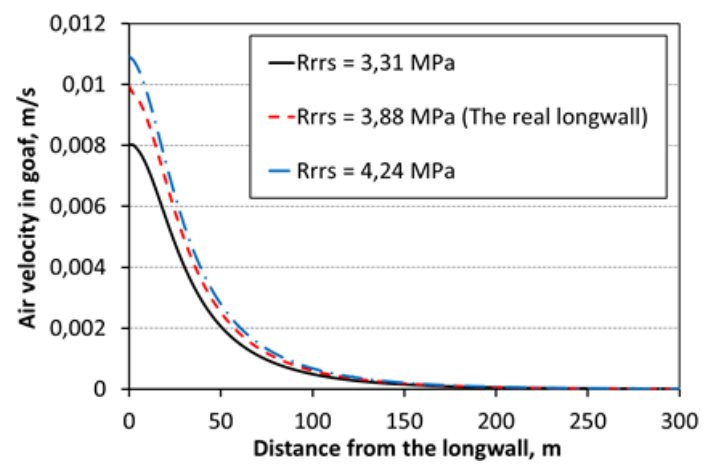

a

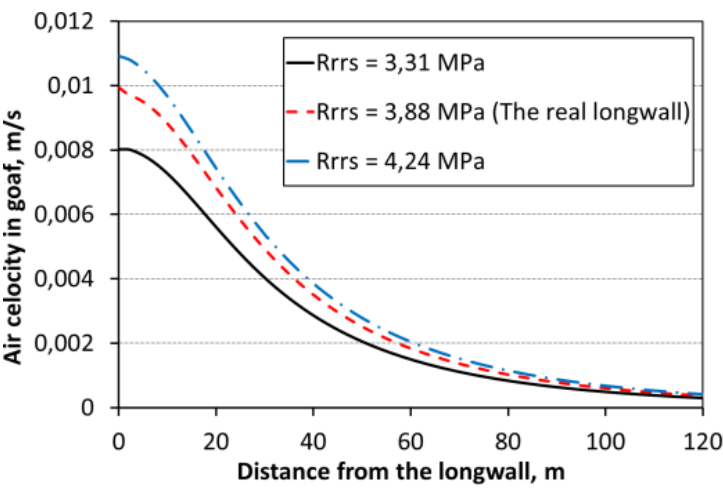

b

Fig. 8 Courses of changes in velocity of air flowing through the gob along the measurement line „CENTER“
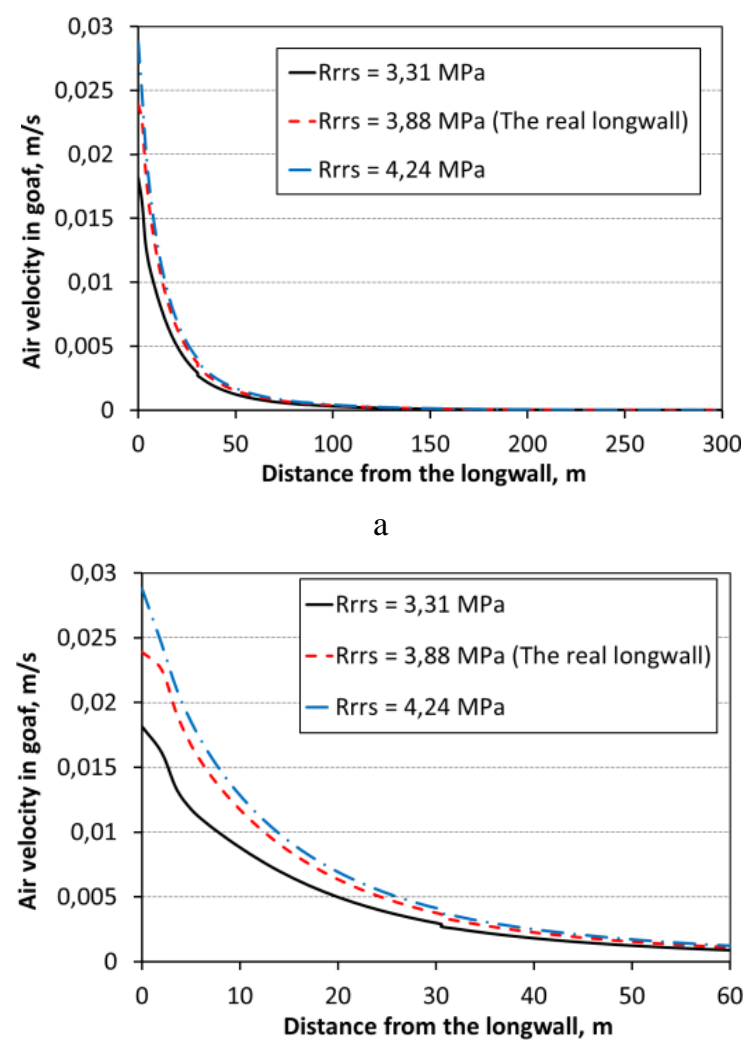

b

Fig. 9 Courses of changes in velocity of air flowing through the gob along the measurement line „OUTLET“

In Fig. 10 there is presented velocities distribution of air stream flowing through goaf with caving at the distance $5 \mathrm{~m}, 50 \mathrm{~m}, 200 \mathrm{~m}$ and $300 \mathrm{~m}$ from the longwall along 
parallel line to the front of the longwall for different values of destratification resistance of roof rocks.

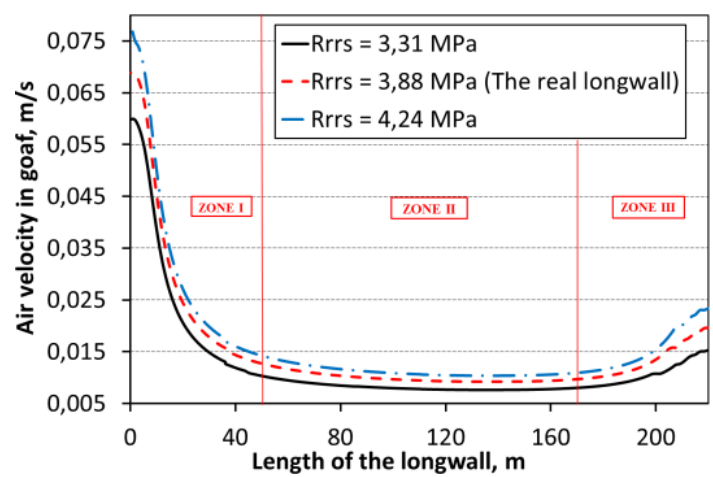

a

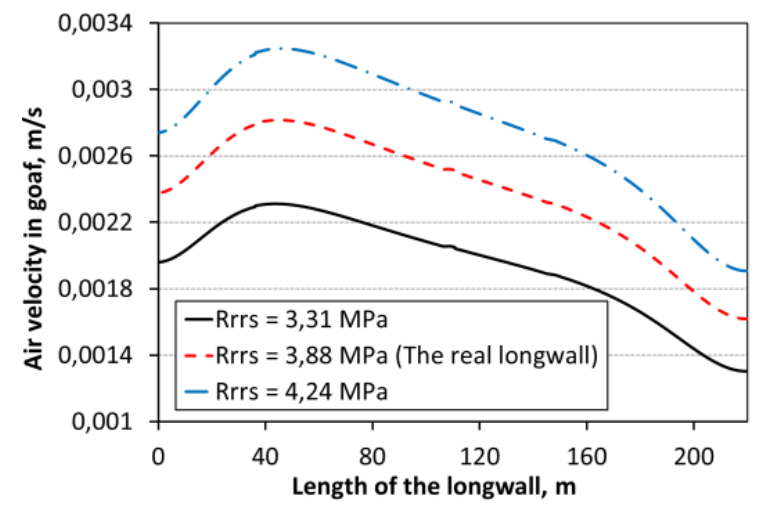

b

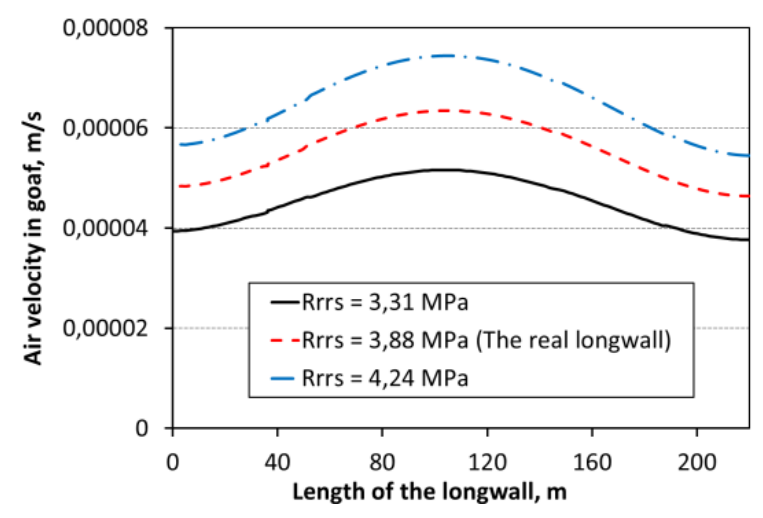

c

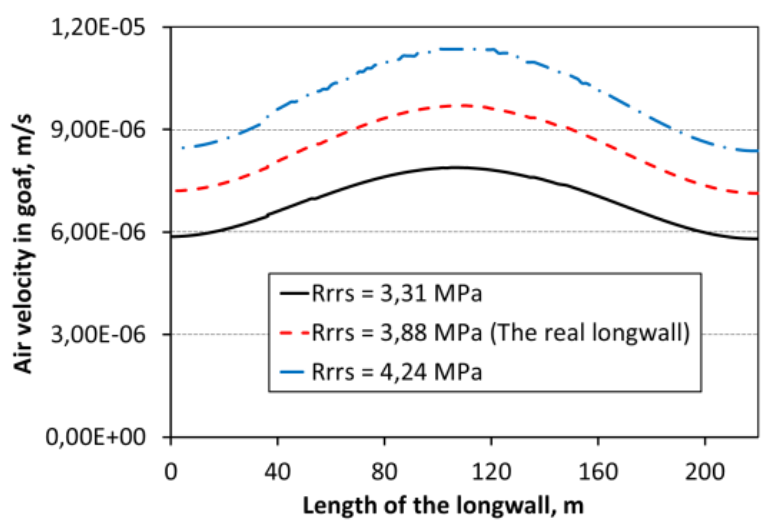

d

Fig. 10 Velocities distribution of air stream flowing through goaf with caving at the distance $5.0 \mathrm{~m} \mathrm{(a)}, 50.0 \mathrm{~m}$ (b), $200.0 \mathrm{~m}$ (c) and $300.0 \mathrm{~m}(\mathrm{~d})$
In the analyzed cases, at initial segment of goaf with caving velocity of air has the greatest value from the side of air inlet to the gobs and from the outlet side of air from these gobs to operating area of longwall. Flow in this area has turbulent character, because this is area in which still there was no full detachment of rocks from roof and their caving to selected area. The lowest value of air velocity in this section of gobs occurs in their central part. Therefore, in gobs distinct zones with different parameters of air flow can be distinguished. First zone occurs in gobs behind the front of longwall, from inlet side of air to the longwall (crossing of longwall with bottom gate), second middle zone is situated on the longwall length, and third is located behind the front longwall from side of air outlet to the longwall (crossing of longwall with top gate). In the first zone, independently from weighted mean value of destratification resistance of roof rocks forming the gobs, there occur high intensities of air flowing through the gobs and the greatest air stream velocities. Middle zone is characterized by stable velocity of air stream, and third zone - is characterized by again increase of air velocity. In this zone air stream is direct from the gobs to tailgate.

Depending on the distance from the longwall front and gates change of air flow character in gobs is presented. Air flowing through gobs the highest value obtains in central part of gobs, and the lowest from the inlet and outlet side. The highest intensity of filtrated air stream through gobs is directed towards the central part of gobs, and next to outlet of operating longwall are - where the pressure is the smallest. It is also important that at a distance of about $20 \mathrm{~m}$ from the front of the longwall there is change of air flow nature in gobs from turbulent to laminar.

In Table 4 characteristic value for air stream velocity in gobs depending on value of destratification resistance of rocks are presented.

Analysis of obtained results clearly indicates that increase of value of destratification resistance of rocks causes an increase of volumetric air stream incoming into gobs and flowing also through caving zone. Greater volumetric flow of air stream influences also on increase of average velocity of air flowing through goaf with caving. Greater permeability and greater value of destratification resistance of roof rocks causes more intensive ventilation of caving zone.

Table 4

Value for air stream velocity in gobs depending on value of destratification resistance of rocks

\begin{tabular}{|c|c|c|c|}
\hline$R_{r r}, \mathrm{MPa}$ & $\begin{array}{c}\text { Average } \\
\text { velocity, m/s }\end{array}$ & $\begin{array}{c}\text { Minimum } \\
\text { velocity, m/s }\end{array}$ & $\begin{array}{c}\text { Maximum } \\
\text { velocity, m/s }\end{array}$ \\
\hline 3.31 & 0.000963 & $3.39 \mathrm{E}-08$ & 0.401761 \\
\hline 3.88 & 0.001168 & $4.82 \mathrm{E}-08$ & 0.468012 \\
\hline 4.24 & 0.001331 & $5.19 \mathrm{E}-08$ & 0.514649 \\
\hline
\end{tabular}

\section{Conclusions}

Parameter which has the biggest impact on air flow through goaf with caving is their permeability. which measure is permeability coefficient. Value of this coefficient depends on type of roof rock forming caving and their strength properties. and primarily by the value of destratification resistance of rocks.

Value of destratification resistance of roof rocks very significant impact on physical parameters of air flow through goaf with caving i.e. on static pressure of air and 
velocity of filtration. Lower value of destratification resistance of roof rocks forming goaf with caving causes decreased of their permeability and decreased velocity and greater pressure differences of air in gobs. In a case of greater values of destratification resistance of rocks one can observe opposite phenomenon.

Therefore. one can conclude that gobs created by roof rocks with different values of destratification resistance create different conditions for air flowing through these gobs. Analysis of obtained results clearly indicate that destratification resistance of rocks causes increase of permeability coefficient of gobs. and that influences on volumetric increase of air stream inlet and flowing through caving roof.

Research methodology and obtained results presented in the article. allow to clearly determine the impact of type of the roof rocks on the air parameters flowing through the gobs. However, the credibility of these results depends on determined physical parameters of rocks forming the goaf with caving and on the measurements of parameters of air flow and methane content of seam.

Obtained results prove that application of numerical methods together with (partial) results in obtained real conditions can be successfully used for variant analyses of process connected with ventilation of underground mine headings. and also in the analyses of emergency states.

\section{Acknowledgement}

Publication supported as a part of the Rector's grant in the area of scientific research and development works. Silesian University of Technology, No 13/030/RGJ17/002801.

\section{References}

1. Szlazak, J. 2001. The determination of a co-efficient of longwall gob permeability, Archives of Mining Science 46: 451-468.

2. Brodny, J.; Tutak, M. 2016. The impact of the flow volume ventilation to the location of the special hazard spontaneous fire zone in goaf with caving of operating longwalls, SGEM 2016, Science and Technologies in Geology, Exploration and Mining: 897-904. http://dx.doi.org/10.5593/SGEM2016/B12/S03.115.

3. Tang, M.; Jiang, B.; Zhang, R.; Yin, Z.; Dai, G. 2016. Numerical analysis on the influence of gas extraction on air leakage in the gob, Journal of Natural Gas Science and Engineering 33: 278-286. https://doi.org/10.1016/j.jngse.2016.05.006.

4. Di, Z. Q.; Ding, G. X.; Zuo, S. X. et al. 1993. The theoretical calculation and observation analysis of the "Three Zones" in the goaf of fully mechanized face with top coal drawing, J. China Univ. Min. Technol. 22 (1): 8-16.

5. Brodny, J.; Tutak, M. 2016. Determination of the zone endangered by methane explosion in goaf with caving of operating longwalls, SGEM 2016: 299-306. http://dx.doi.org/10.5593/SGEM2016/B12/S03.039.

6. Kidybiński, A. 1982. The Basics of geotechnical mine, Publishing house ,Śląsk”. Katowice.

7. John, A.; John, M.; Bartela, A. 2016. Numerical homogenization of the foamed metal structures, J. Mechanika 22(5): 343-348. http://dx.doi.org/10.5755/j01.mech.22.5.16689.
8. Sobieski, W.; Lipiński, S.; Dudda, W. et al. 2016. Granularne ośrodki porowate. Olsztyn 2016.

9. Wang, J.G.; Kabir, A.; Liu, J.S. et al. 2012. Effects of non-Darcy flow on the performance of coal seam gas wells, Int. J. Coal Geol. 93: 62-74. https://doi.org/10.1016/j.coal.2012.01.013.

10. Xia, T.Q.; Zhou, F.B.; Liu, J.S. et al. 2014. A fully coupled hydro-thermo-mechanical model for the spontaneous combustion of underground coal seams, Fuel 125: 106-115. https://doi.org/10.1016/j.fuel.2014.02.023.

11. Bachmat, Y. 1965. Basic Transport Coefficients as Aquifer Characteristics, I.A.S.H. Symposium Hydrology of Fractured Rocks, Dubrovnik, 63-76.

\author{
J. Brodny. M. Tutak. A. John
}

ANALYSIS OF INFLUENCE OF TYPES OF ROCKS FORMING THE GOAF WITH CAVING ON THE PHYSICAL PARAMETERS OF AIR STREAM FLOWING THROUGH THESE GOB AND ADJACENT HEADINGS

S u m m a r y

In the paper there are presented results of influence of types of rocks forming the goaf with caving on the physical parameters of air stream flowing through these goaf and adjacent headings.

It was assumed. that goaf with caving are porous medium. which permeability and porosity depends on the distance from the front longwall and from stratification resistance of rocks forming the heap. On the base of stand tests values of stratification resistance of rock littering at the roof of tested longwalls were determined. The main aim of the tests was to determine an impact of type of rock littering in mined seam on values and distribution of velocity and pressure of air stream in the gobs This aim was realized by a determination of value of stratification resistance of roof rocks on the tested parameters of air stream flowing through these gob. Analysis was performed in the ANSYS Fluent software.

Modeling studies were performed for real exploitation longwall and additionally for two types of roof created with the most often presented rocks. For each of these systems distributions of velocities and static pressure along assumed measurement lines were determined. Analysis included determination of physical parameters of the air stream flowing through the gob for real exploitation conditions of this longwall and additionally for assumed two (the most often presented in reality) variants of rock presented in the roof of mining longwall.

Developed research methodology and obtained results should be use during selection of ventilation parameters and preventive actions connected with reduce methane and fire hazard in underground mining.

Keywords: permeability, porous media, gobs, air flow, stratification resistance of roof rock. 